\title{
SISTEMATIZAÇÃO DE EXPERIÊNCIAS: CONCEITO E REFERÊNCIAS PARA FORMAÇÃO DE PROFESSORES DE CIÊNCIAS
}

\section{SYSTEMATIZATION OF EXPERIENCES: CONCEPT AND REFERENCES FOR SCIENCE TEACHERS' EDUCATION}

\author{
Daniele Bremm ${ }^{1}$ \\ ORCID iD: $\underline{0000-0003-3473-9383}$
}

Roque Ismael da Costa Güllich $2^{2}$

ORCID iD: 0000-0002-8597-4909

\begin{abstract}
RESUMO
O artigo apresenta como temática processo de Sistematização de Experiências (SE) junto à formação de professores de Ciências. Objetivamos identificar as concepções acerca da sistematização em contexto brasileiro, para que possamos ampliar e aprofundar esse tema de forma a construir um conceito e processo possível e referenciado para ser trabalhado durante a formação de professores de Ciências. Para tanto, realizamos estudo do tipo estado do conhecimento, envolvendo a busca por referências teóricas internacionais e pesquisas brasileiras na perspectiva de um processo cíclico de InvestigaçãoAção. O corpus da pesquisa apresentou 14 trabalhos brasileiros, após o aprofundamento conceitual, concebemos a Sistematização de Experiências como um macroprocesso central ao desencadeamento da Investigação-Formação-Ação (IFA). Esta proposição reitera a importância do desenvolvimento da SE para a dimensão formativa da IFA, contribui para sua efetivação integral e se estabelece como modelo possível para a formação de professores de Ciências.
\end{abstract}

Palavras-chaves: Investigação-Ação. Investigação-Formação-Ação. Formação continuada. Reflexão Crítica. Pesquisa-Ação.

\begin{abstract}
The article presents as thematic the process of Systematization of Experiences (SE) alongside the science teachers' education, we aim to identify the conceptions about the systematization in the brazilian context, in order to be able to enlarge and deepen this concept, the way to build a concept and the possible process and cited to be processed during the science teachers' education. Therefore, we made a study like state of knowledge involving the seek for international theoretical references and Brazilian researches to outlook a cyclic process of Investigation-Action. The corpus of the researches presented 14 brazilian works, which were analyzed in the light of the Discursive Textual Analysis. Results built point to a final category that comprehends our conception about the SE process, from elements found in brazilian thesis and dissertations review, collated by the literature of the field. Thereby, in reference of teacher formation, after conceptual deepening, we conceived the Systematization of Experiences as a central macro process triggering the Action-Training-Research (IFA). This proposition reiterates the
\end{abstract}

\footnotetext{
${ }^{1}$ Mestranda em Ensino de Ciências pela Universidade Federal da Fronteira Sul (UFFS). Bolsista Institucional na Universidade Federal da Fronteira Sul (UFFS), Cerro Largo, Rio Grande do Sul, B. Endereço para correspondência: Rua São Fernando, 174, São Fernando, Cerro Largo, Rio Grande do Sul, Brasil, CEP: 97900000. E-mail: bremmdaniele@ gmail.com.

${ }^{2}$ Doutor em Educação nas Ciências pela Universidade Regional do Noroeste do Estado do Rio Grande do Sul (UNIJUÍ). Professor adjunto na Universidade Federal da Fronteira Sul (UFFS), Cerro Largo, Rio Grande do Sul, Brasil. Endereço para correspondência: Rua Francisco Silvério Renz, 129, Mucha, Giruá, Rio Grande do Sul, Brasil, CEP: 98870-000 E-mail: bioroque.girua@gmail.com.
} 
importance of developing SE to formative dimension of IFA, it contributes to its full effectuation and establishes itself as a possible model to science teachers' education.

Keywords/Palabras clave: Action Research. Action-Training-Research. Continued Education. Critical Reflexion.

\section{POR QUE E COMO SISTEMATIZAR EXPERIÊNCIAS?}

A escrita deste artigo perpassa uma espiral autorreflexiva dos autores do trabalho de modo a ser sistematizado um conhecimento a partir de um ciclo formativo (GÜLLICH, 2013), de caráter desenvolvimentista, os quais foram analisados à luz da Análise Textual Discursiva. Os resultados construídos apontaram para a categoria final que compreende a nossa concepção sobre o processo de SE, a partir dos elementos encontrados na revisão das teses e dissertações brasileiras, cotejada pela literatura da área. Assim, no que tange à formação de professores, é com base nas etapas de observação, problematização, planificação, ação, avaliação e modificação, permeadas pela reflexão, que se facilita o desenvolvimento da aprendizagem e do processo de conceitualização (ALARCÃO, 2010).

Iniciamos esta investigação com base em observações do processo de formação inicial e continuada realizado nos Ciclos Formativos em Ensino de Ciências ${ }^{3}$, projeto de extensão do Grupo de Estudos e Pesquisa em Ensino de Ciências e Matemática (GEPECIEM), da Universidade Federal da Fronteira Sul - UFFS, campus Cerro Largo. Este contexto tem a Investigação-Formação-Ação (IFA) como pressuposto de formação de professores, em que a reflexão é concebida como categoria formativa (GÜLLICH, 2013). Dentro do modelo da IFA, a sistematização é utilizada como elemento formativo (PERSON; BREMM; GÜLLICH, 2019).

Com relação a isso, em pesquisa anterior, Bremm (2019) constatou que, nos Ciclos Formativos, a sistematização que ocorre é capaz de desencadear uma série de elementos formativos, sendo estes: as narrativas reflexivas no Diário de Formação (DF), o espelhamento de práticas e o diálogo formativo, todos estes levam o professor a refletir sobre a sua prática criticamente, de forma individual e coletiva. Isso nos mostrou que o processo de sistematização é imprescindível para que a IFA seja desencadeada de forma plena, pois percebemos que "o diálogo entre os pares e a sistematização da experiência assumem papéis relevantes na formação dos professores, possibilitando compreender a IFA como um modelo de formação em que a

\footnotetext{
${ }^{3}$ Fazem parte do coletivo de formação "Ciclos Formativos” dois subgrupos: um de Ciências e outro de Matemática, que são desenvolvidos de modo articulado em Programa de Extensão. Nesta pesquisa, interessa-nos particularmente investigar a formação de professores de Ciências e Biologia, de modo que só olharemos para o subgrupo de Ciências. Estes encontros de formação são realizados pelo GEPECIEM da UFFS.
} 
reflexão é a base e a finalidade" (BREMM, 2019, p. 25). Defendemos, com base na análise deste contexto já situado, que a Sistematização de Experiências (SE) é fundamental para o desenvolvimento da IFA durante os Ciclos Formativos e faz parte das garantias necessárias para que esta desencadeie a reflexão formativa (BREMM, 2019).

Diante da importância que o processo de SE tem demonstrado, com relação ao desenvolvimento da IFA e da reflexão crítica, durante a formação inicial e continuada de professores de Ciências nos Ciclos Formativos, nos propomos pensar e problematizar: qual o conceito de SE que melhor apreende os processos de formação de professores de Ciências?

A planificação da investigação aqui empreendida constitui-se como uma pesquisa de abordagem qualitativa (LÜDKE, ANDRÉ, 2001), ancorada num processo de IFA (ALRCÃO, 2010; GÜLLICH, 2013), em que se procedeu um estudo do tipo estado do conhecimento (ROMANOWSKI; ENS, 2006).

Nossa $a c ̧ a ̃ o$ foi iniciada pela busca de: i) referências teóricas sobre o processo de IFA e SE na literatura da área sobre a formação de professores na perspectiva da Investigação-Ação (IA) para dar suporte às compreensões e cotejar os dados da outra busca; ii) busca de dados realizada no site do Instituto Brasileiro de Informação em Ciência e Tecnologia (IBICT), a partir da Base de Dados de Teses e Dissertações (BDTD), de onde destacamos os trabalhos acadêmicos através do uso de expressões: "sistematização de experiências e formação de professores"; "sistematização de experiências". As expressões nos remeteram inicialmente a 1012 teses e dissertações.

Em seguida, realizamos a leitura preliminar dos trabalhos, com o intuito de demarcar teses e dissertações que conceitualizassem e/ou apresentassem o seu enfoque em processos de sistematização ${ }^{4}$, resultando em 38 trabalhos acadêmicos. Estas teses e dissertações préselecionadas foram submetidas a um novo descritor: "formação de professores", resultando 14 trabalhos e assim obtivemos um conjunto de teses e dissertações "capaz de produzir resultados válidos e representativos em relação aos fenômenos investigados" (MORAES, GALIAZZI, 2011, p. 17). Estes 14 trabalhos passaram a ser o corpus da pesquisa, sendo, destes, sete teses e sete dissertações, que foram analisadas nesta investigação. Estes trabalhos compreendem os anos de 1995 a 2017, sendo os anos de maior ocorrência 2008, 2009 e 2016, com dois trabalhos ao ano.

\footnotetext{
${ }^{4}$ Em nossa busca, utilizamos o conceito de Sistematização de forma ampla e aberta, admitindo, portanto, todas as variações possíveis e acolhendo os diferentes entendimentos, de modo a analisar os diferentes enfoques e aprofundarmos esse conceito, de forma a construir um conceito possível de ser trabalhado durante a formação de professores de Ciências.
} 
Os 14 trabalhos selecionados foram analisados com base na Análise Textual Discursiva (ATD) (MORAES, GALIAZZI, 2011). A ATD consiste em um ciclo de análise que contempla três etapas, sendo elas: a Impregnação ou Unitarização, a Auto-Organização ou Categorização e a Exploração de sentidos ou Produção de Metatexto (MORAES, GALIAZZI, 2011). A Unitarização consiste em analisar os textos em seus detalhes, fragmentando estes até atingir as suas unidades constituintes, "com essa fragmentação ou desconstrução pretende-se conseguir perceber os sentidos dos textos em diferentes limites de seus pormenores, ainda que se saiba que um limite final e absoluto nunca é atingido" (MORAES, GALIAZZI, 2011, p. 18). Após a desconstrução dos textos, emergem as Unidades de Significado, que "são sempre identificadas em função de um sentido pertinente aos propósitos de pesquisa” (MORAES, GALIAZZI, 2011, p. 19). Sobre esse processo é importante destacar que:

é preciso desestabilizar a ordem estabelecida, desorganizando o conhecimento existente. Tendo como referência as ideias dos sistemas complexos, este processo consiste em levar o sistema semântico ao limite do caos. A unitarização é um processo que produz desordem a partir de um conjunto de textos ordenados. Torna caótico o que era ordenado. Neste espaço uma nova ordem pode constituir-se à custa da desordem. O estabelecimento de novas relações entre os elementos unitários de base possibilita a construção de uma nova ordem, representando novas compreensões, em relação aos fenômenos investigados (MORAES, GALIAZZI, 2011, p. 21).

A etapa seguinte é o processo de Categorização que, por sua vez, exige a construção de relações entre as Unidades de Significado, processo este que ocorre mediante a leitura e releitura das Unidades de Significado, de modo a combiná-las e classificá-las, o que resultará em um sistema de categorias iniciais, que serão novamente agrupadas por semelhanças em categorias intermediárias e posteriormente em categorias finais (MORAES, GALIAZZI, 2011). Com a elaboração das categorias finais, podemos partir para a última etapa, que é a Produção de um Metatexto, que se caracteriza por um esforço empreendido a fim de apresentar uma nova compreensão que vai se apresentando como resultado dos passos anteriores (MORAES, GALIAZZI, 2011). Como salientam Moraes e Galiazzi (2011, p. 23), “o conjunto das categorias constituem os elementos de organização do metatexto que se pretende escrever. É a partir delas, que se produzirão as descrições e interpretações que comporão o exercício de expressar as novas compreensões possibilitadas pela análise".

As teses e dissertações analisadas foram identificadas e classificadas, por meio de uma tabela síntese: Tabela 1, que apresenta os trabalhos selecionados, para esta pesquisa, de acordo com os seguintes elementos: 1- Identificação dos trabalhos para posterior discussão; 2- Título e Autor do trabalho; 3- Instituição e ano de publicação; 4- Tipo de trabalho; 5- Principais referências teóricas utilizadas pelos autores. Para facilitarmos o tratamento dos trabalhos 
analisados ao longo da análise, estes foram nominados como T1, T2, T3... assim, por diante para teses e D1, D2... para dissertações, seguidas do seu ano de publicação no IBICT: T1, 1995 e assim por diante.

Tabela 1 - Pesquisas Brasileiras sobre Sistematização de Experiências

\begin{tabular}{|c|c|c|c|c|}
\hline $\mathbf{N}$ & Título e Autor & $\begin{array}{l}\text { IES } \\
\text { Ano }\end{array}$ & $\begin{array}{l}\text { Tipo de } \\
\text { trabalho }\end{array}$ & Referências teóricas \\
\hline $\begin{array}{c}1 \\
\text { T1 } \\
1995\end{array}$ & $\begin{array}{l}\text { A formação em serviço de docentes de } \\
\text { adultos: pós-alfabetização (PRADA) }\end{array}$ & $\begin{array}{l}\text { UNICAMP } \\
1995\end{array}$ & $\mathrm{~T}$ & $\begin{array}{lr}\text { BARBIER; } & \text { BOSCO; } \\
\text { DEMO; } & \text { BRANDÃO } \\
\text { STRECK } & \end{array}$ \\
\hline $\begin{array}{c}2 \\
\text { T2 } \\
2005\end{array}$ & $\begin{array}{l}\text { Ação docente formação continuada e } \\
\text { inclusão escolar (ANDRADE) }\end{array}$ & $\begin{array}{l}\text { UFRGS } \\
2005\end{array}$ & $\mathrm{~T}$ & CARR e KEMMIS \\
\hline $\begin{array}{c}3 \\
\text { T3, } \\
2007\end{array}$ & $\begin{array}{l}\text { Luzes... câmera... reflexão; formação } \\
\text { inicial de professores mediada por filmes } \\
\text { (MAYRINK) }\end{array}$ & $\begin{array}{l}\text { PUC -SP } \\
2007\end{array}$ & $\mathrm{~T}$ & FREIRE \\
\hline $\begin{array}{c}4 \\
\text { D1, } \\
2008\end{array}$ & $\begin{array}{l}\text { Professor de inglês ou professor de inglês } \\
\text { educador na escola pública? (PEREZ) }\end{array}$ & $\begin{array}{l}\text { PUC- SP } \\
2008\end{array}$ & $\mathrm{D}$ & FREIRE \\
\hline $\begin{array}{c}5 \\
\text { D2, } \\
2008\end{array}$ & $\begin{array}{l}\text { A sistematização participativa de cursos } \\
\text { de capacitação em solos para professores } \\
\text { da educação básica (CIRINO) }\end{array}$ & $\begin{array}{l}\text { UFV } \\
2008\end{array}$ & $\mathrm{D}$ & $\begin{array}{l}\text { JARA; FALKEMBACH; } \\
\text { TOMAZI; GEILFUS; }\end{array}$ \\
\hline $\begin{array}{c}6 \\
\text { D3, } \\
2009\end{array}$ & $\begin{array}{lrrr}\text { Dificuldade } & \text { de } & \text { estudar online; } & \text { uma } \\
\text { narrativa } & \text { de } & \text { experiências } & \text { de } \\
\text { aprendizagem (BURIAN) } & \end{array}$ & $\begin{array}{l}\text { PUC- SP } \\
2009\end{array}$ & $\mathrm{D}$ & FREIRE \\
\hline $\begin{array}{c}7 \\
\text { T4, } \\
2009\end{array}$ & $\begin{array}{l}\text { A formação dos educadores como eixo do } \\
\text { desenvolvimento curricular; o projeto de } \\
\text { educação dos posseiros do Paraná PEPO } \\
\text { (LUCAS) }\end{array}$ & $\begin{array}{l}\text { PUC - SP } \\
2009\end{array}$ & $\mathrm{~T}$ & $\begin{array}{ll}\text { JARA; } & \text { FALKEMBACH; } \\
\text { SOUZA } & \end{array}$ \\
\hline $\begin{array}{c}8 \\
\text { T5 } \\
2011\end{array}$ & $\begin{array}{l}\text { Prática discursiva de formação de } \\
\text { professores alfabetizadores de jovens e } \\
\text { adultos em uma experiência de educação } \\
\text { popular (SILVA) }\end{array}$ & $\begin{array}{l}\text { UFPE } \\
2011\end{array}$ & $\mathrm{~T}$ & JARA \\
\hline $\begin{array}{c}9 \\
\text { D4, } \\
2012\end{array}$ & $\begin{array}{l}\text { O currículo integrado na educação de } \\
\text { jovens e adultos (LOTTERMANN) }\end{array}$ & $\begin{array}{l}\text { UNIJUÍ } \\
2012\end{array}$ & $\mathrm{D}$ & $\begin{array}{l}\text { FALKEMBACH; } \\
\text { HADDAD E DI PIERRO; } \\
\text { JARA; SOUZA; FREIRE }\end{array}$ \\
\hline $\begin{array}{c}10 \\
\text { D5, } \\
2013\end{array}$ & $\begin{array}{l}\text { Professor aprendiz; formação de docentes } \\
\text { protagonizada por seus pares na rede } \\
\text { estadual do Ceará (MENDES) }\end{array}$ & $\begin{array}{l}\text { UFJF } \\
2013\end{array}$ & $\mathrm{D}$ & $\begin{array}{l}\text { ALARCÃO; CARVALHO; } \\
\text { FALSARELLA; } \\
\text { GUIMARÃE; IBERNÓN }\end{array}$ \\
\hline $\begin{array}{c}11 \\
\text { D6, } \\
2015\end{array}$ & $\begin{array}{l}\text { A educação popular na práxis do pró } \\
\text { jovem campo- saberes da terra no Espírito } \\
\text { Santo (FERREIRA) }\end{array}$ & $\begin{array}{l}\text { UFES } \\
2015\end{array}$ & $\mathrm{D}$ & $\begin{array}{l}\text { FREIRE; GHISO; MEJÍA; } \\
\text { JARA; }\end{array}$ \\
\hline $\begin{array}{c}12 \\
\text { T6, } \\
2016\end{array}$ & $\begin{array}{l}\text { A experiência formativa na } 1^{\mathrm{a}} \text { licenciatura } \\
\text { em pedagogia do PARFOR/UEA e seus } \\
\text { sentidos constituintes à experiência } \\
\text { laboral na educação infantil em uma } \\
\text { escola municipal de AUTAZES/AM } \\
\text { (CARNEIRO) }\end{array}$ & $\begin{array}{l}\text { UFAM } \\
2016\end{array}$ & $\mathrm{~T}$ & $\begin{array}{l}\text { PALMA; JARA; STRECK; } \\
\text { FALKEMBACH; SOUZA }\end{array}$ \\
\hline
\end{tabular}




\begin{tabular}{|c|c|c|c|c|}
\hline $\begin{array}{c}13 \\
\text { D7, } \\
2016\end{array}$ & $\begin{array}{l}\text { A sistematização dos saberes docentes na } \\
\text { formação inicial de professores de } \\
\text { química na universidade federal do } \\
\text { espírito santo (ROSA) }\end{array}$ & $\begin{array}{l}\text { UFES } \\
2016\end{array}$ & $\mathrm{D}$ & $\begin{array}{l}\text { GAU-THIER, TARDIF, } \\
\text { MALDANER, FOERSTE e } \\
\text { PIMENTA }\end{array}$ \\
\hline $\begin{array}{c}14 \\
\text { T7, } \\
2017\end{array}$ & $\begin{array}{l}\text { A educação popular nas experiências e } \\
\text { práticas de integração curricular no proeja } \\
\text { do IFES (SCOPEL) }\end{array}$ & $\begin{array}{c}\text { UFES } \\
2017\end{array}$ & $\mathrm{~T}$ & $\begin{array}{l}\text { BRANDÃO; GONZÁLEZ; } \\
\text { FALKEMBACH; FREIRE; } \\
\text { GHISO; JARA; MEJÍA;; } \\
\text { STRECK; CARRILLO; }\end{array}$ \\
\hline
\end{tabular}

Fonte: Elaborado pelos Autores, 2020. Notas: 1. ID- Identificação do trabalho; 2. IES- Instituições de Ensino Superior; 3. Tipo de trabalho: D - Dissertação, T - Tese.

Planificada, possível de ser empreendida toda a ação e na expectativa de melhor compreender o papel da SE em contextos de formação de professores, é que realizamos este levantamento de teses e dissertações sobre SE no IBICT. Ademais, procuramos identificar os conceitos e os referenciais utilizados nas pesquisas, bem como o esforço teórico pelo resgate da literatura da área apresentado no texto para aprofundarmos o conceito de SE. Este aparato aqui exposto fez parte da etapa de avaliação, em que foi possível analisar os resultados construídos e depreendidos ao longo da investigação.

A partir da investigação, com base nos dados empíricos (pesquisas analisadas) e teóricos (literatura da área) temos como pretensão chegar a compreensão do papel da SE no processo de IFA articulado ao contexto de formação de professores de Ciências. Portanto, a revisão do conceito de SE para o contexto brasileiro torna-se relevante para que possamos ampliar e aprofundar esse conceito, de forma a construir um conceito possível de ser trabalhado para a formação de professores de Ciências. A defesa final, é aqui compreendida na espiral autorreflexiva como modificação da problemática/problema de investigação.

Ao longo desta IFA, pretendemos manter o foco na reflexão como categoria formativa que dá sentido às compreensões. Refletir sobre as ações decorrentes dos cenários teóricos observados, buscando compreendê-los em perspectiva, para depreendermos, das aprendizagens, um conceito possível.

\section{DAS REFERÊNCIAS ÀS DEFESAS DA SISTEMATIZAÇÃO DAS EXPERIÊNCIAS}

A constituição docente do professor não se dá somente pela sua prática. Os saberes que constituem o professor têm origem nos processos de formação dos quais estes participam, bem como nas teorias educacionais as quais estão submersos (NÓVOA, 1995). Segundo Nóvoa (1995, p. 24), a formação de professores deve: “desempenhar um papel importante na configuração de uma nova profissionalidade docente, estimulando a emergência de uma cultura 
profissional no seio do professorado e de uma cultura organizacional no seio das escolas". No entanto, para que isso, ocorra, a formação deve ser desenvolvida por meio "de um trabalho de reflexividade crítica sobre as práticas e de (re)construção permanente de uma identidade pessoal" (NÓVOA, 1995, p. 25).

A IFA vem sendo apontada como modelo de formação de professores (ALARCÃO, 2010; GÜLLICH, 2013; KIEREPKA; GÜLLICH, 2016; PERSON, BREMM; GÜLLICH, 2019), sendo que "no terreno da educação, a investigação-ação é utilizada para o desenvolvimento curricular [e para] o melhoramento de programas de ensino" (CARR; KEMMIS, 1988, p.174 [tradução própria]), uma vez que leva em conta os elementos anteriormente apontados. A IFA, segundo Carr e Kemmis (1988), é um processo de transformação das práticas em caráter contínuo, que precisa ter como pano de fundo a teoria da racionalidade crítica, que parte da ideia de um professor que não separa o pensar e tomando sua ação como complexa e reflexiva (CARR; KEMMIS, 1988).

A teoria educacional crítica, que toma a perspectiva da reflexão crítica como central, aponta para a inovação curricular por meio de processos de transformação dos sujeitos (CARR; KEMMIS, 1988). Uma forma de tornar a formação continuada eficaz é discutir a reorganização curricular através da formação compartilhada, pois é por meio das interações que o processo reflexivo flui e oferece um caminho de transformações que passam a constituir os sujeitos participantes do processo (ZANON, 2003).

Por isso, Güllich (2013) propõe ampliação do modelo de Investigação-Ação (IA) para IFA, pois, uma vez que o processo de investigação esteja marcado pela reflexão formativa; que se desenvolva num coletivo sobre a própria prática; que investigue sobre a ação docente, este se constitui em um momento de formação de professores. Alarcão (2010) também defende a IFA, ao compreender que, em se tratando de educação, os processos investigativos, de pesquisa da prática docente, necessariamente formam/constituem o professor.

A pesquisa da prática é o processo de reflexão sobre e para a melhoria da prática, é um movimento de transformação e melhoria das práticas pedagógicas, uma intervenção que nasce e serve para a própria prática do professor envolvido na IA (CARR; KEMMIS, 1988). Os professores em formação no contexto da IA:

não se limitam a expor (falar) suas práticas, mas instituem discursos acerca das práticas [...] os investigadores ativos chegam a desenvolver suas próprias teorias educacionais sobre a base do conhecimento pessoal, através de sua expressão na práxis e para seu desenvolvimento sistemático no discurso de comunidades autorreflexivas de investigadores ativos (CARR; KEMMIS, 1988, p. 202[tradução própria]). 
Para que a reflexão crítica, sobre, na e para a transformação das práticas (ALARCÃO, 2010), ocorra de fato, alguns elementos/processos precisam ser desencadeados durante a IFA, sendo eles: as narrativas reflexivas construídas no DF, o espelhamento de práticas, o diálogo formativo e a SE. Ademais, defendem que os diários são os nascedouros dos relatos e que os relatos de experiências são requisitos necessários à SE. (GÜLLUCH, 2013; PERSON; BREMM; GÜLLICH, 2019; BREMM, 2019).

Importante neste cenário teórico termos em pauta a defesa de Larrosa (2002, p. 21), de que "a experiência é o que nos passa, o que nos acontece o que nos toca" a experiência "requer parar para pensar, parar para olhar, parar para escutar [...] abrir os olhos e os ouvidos, falar sobre o que nos acontece, aprender a lentidão, escutar aos outros, cultivar a arte do encontro" (p. 24). A noção de experiência de Larrosa (2002) é um pressuposto ou pano de fundo que coloca ao conceito a subjetivação, algo que devemos ter em mente e pelo qual nosso conceito deve perpassar. Ademais, "a troca de experiências e a partilha de saberes consolidam espaços de formação mútua, nos quais cada professor é chamado a desempenhar, simultaneamente, o papel de formador e de formando" (NÓVOA, 1995, p. 26), o que está diretamente relacionado com o pressuposto da IA crítica, no que concerne ao efeito do processo de IA na transformação de práticas em caráter coletivo (CARR; KEMMIS, 1988).

Garcia (1992) defende a descrição de casos como instrumento de aperfeiçoamento dos professores. Esta estratégia está pautada em "uma situação de ensino, em que se descrevem pormenorizadamente as características dos participantes na situação (professores e alunos), bem como as características do contexto (escola, aula) e as características pedagógicas da situação" (GARCIA, 1992, p. 71). É por meio destas informações sistematizadas que se propicia a reflexão e o debate, ajudando os professores a desenvolverem processos de análise crítica e de resolução de problemas pedagógicos.

Gauthier et al. (2006) se refere aos saberes experienciais de uma forma bem específica, afirmando que estes são capazes de prover elementos para a reflexão, inclusive a respeito da importância da própria experiência prática na constituição docente. Para Gauthier et al. (2006), os saberes experienciais correspondem aos conhecimentos construídos pelos professores por meio de reflexões individuais. Segundo a perspectiva de Tardif (2002), os saberes experienciais que constituem o professor são resultados de um processo individual, mas que ao mesmo tempo são legitimados por meio de processos de compartilhamento e socialização profissional. Acreditamos que é por meio da socialização de experiências que o professor (re)elabora ou produz seus saberes docentes, especialmente os experienciais, a integração dos saberes à prática 
docente acontece por processos de socialização. Portanto, os saberes docentes não podem ser caracterizados unicamente como uma construção individual.

Segundo a perspectiva da educação popular, as experiências são relevantes por desencadearem a produção do conhecimento (FREIRE, 2005) e também a construção da identidade dos sujeitos (NÓVOA, 1995). A experiência não é a origem das explicações ou a evidência que fundamenta o conhecimento, mas aquilo que buscamos explicar, aquilo sobre o qual se produz conhecimento (SANTOS; CASTRO, 2014). Levando em conta a importância das experiências para a produção de conhecimentos e a própria construção da identidade dos sujeitos, muitas são as áreas que vêm apostando no processo de SE como recurso para externalizar o conhecimento advindo da prática.

No contexto latino-americano, o processo de SE foi construído a partir da educação popular por volta da metade do século $\mathrm{XX}$, quando começou a redefinir paradigmas, modalidades de intervenção pedagógica e de investigação social (SANTOS; CASTRO, 2014). Na América Latina, o tema da sistematização surge, portanto, sustentado por correntes teóricopráticas como: a educação de adultos, a educação popular, a teologia da libertação e a investigação-ação-participativa (FALKEMBACH, 2000).

Desde que surgiu como modalidade investigativa para as práticas educativas e sociais, a SE tem sido objeto de debates e conflitos em virtude das diversas formas pelas quais ela é compreendida e fundamentada, tanto epistemológica como metodologicamente, o que gerou pluralidade de posturas frente à mesma (CARO, 2019). No entanto, existe acordo entre estes pesquisadores em afirmar que a SE surge de uma preocupação que se aproxima muito dos princípios da IA, que é a de analisar criticamente as práticas em busca da transformação, por meio da compreensão e melhoria das mesmas, gerada no compartilhamento das aprendizagens em coletivo (CARR; KEMMIS, 1988; GÜLLICH, 2013; CARO, 2019).

Segundo Meirelles (2007), são tarefas da SE, pela via da reflexão dar forma e sentido, relacionar o particular com o local para transformar a experiência cotidiana e o saber privado em conhecimento que pode ser socializado. As definições e compreensões acerca da SE permanecem, por vezes, "misturadas a de outros procedimentos e instrumentos metodológicos como a sistematização de informações e de dados, a avaliação de projetos, a investigação e a pesquisa, as etapas de processos formativos, entre outros" (MEIRELLES, 2007, p. 44), no que acreditamos que esta problemática está assim colocada como um processo de investigação/pesquisa. 
Importante também destacar que, no contexto latino-americano, podemos encontrar a "Biblioteca Virtual sobre Sistematización de Experiencias"5, que comporta trabalhos com várias definições sobre a SE, destacaremos algumas: Jara (2006, p. 24) define a sistematização como "interpretação crítica, quer dizer, como o resultado de todo um esforço para compreender o sentido das experiências, tomando distância delas", portanto sistematizar não é apenas fazer uma simples descrição dos processos através de narrativas de experiências formativas, é preciso passar para um nível interpretativo (JARA, 2006). Para Martinic (1998), SE é um processo de reflexão que busca ordenar e organizar o que tem sido a marcha, os processos, os resultados de um projeto, buscando em tal dinâmica as dimensões que podem explicar o rumo que trouxe o trabalho realizado.

Segundo Falkembach (2000, p. 16), “fazer sistematização é colocar-se em situação de aprendizagem frente a esse fazer; é predispor-se a circular, conscientemente e inconscientemente entre os limites do novo e do já vivido". A sistematização permite "refletir ordenadamente a partir da nossa prática submetendo tudo a uma crítica, problematizando e identificando os conflitos e contradições, analisando tudo o que fizemos, buscando os porquês e as relações entre as coisas" (SOUZA, 2000, p. 33). Para Morgan (1995, p. 4 [tradução própria]), a sistematização pode ser compreendida como "uma forma de geração de conhecimento adaptada às condições de trabalho e às habilidades particulares daqueles que estão envolvidos na execução diária das ações [...] para que tenham formas de acessar e processar informações diferentes das os dos intelectuais”. Embora a SE não tenha um significado único, podemos perceber a existência de alguns elementos em comum entre as definições citadas: a reflexão, a geração de conhecimentos, a reflexão crítica, a reconstrução analítica, histórica e interpretativa e o diálogo (MEIRELLES, 2007).

A SE é muito mais do que um simples relato ou uma publicação, constitui-se um processo de reflexão crítica de experiência concreta, com o intuito de provocar processos de aprendizagem. Essa reflexão pode ser entendida como processo metodológico, no qual organizamos conhecimentos, ideias e dados que se encontram dispersos. Esse processo só pode ser realizado pelos atores diretos da experiência a qual se está sistematizando (ECKERT, 2009). Ainda segundo Jara (2006):

\footnotetext{
${ }^{5}$ Desenvolvido pelo Consejo de Educación Popular de América Latina y el Caribe- CEAAL, na plataforma podemos encontrar trabalhos em diversas línguas e desenvolvidos em variados focos (educação, saúde, economia, movimentos sociais, questões de gênero, sustentabilidade e políticas públicas). Link de acesso: http://www.cepalforja.org/sistem/bvirtual/?p=992
} 
os principais pontos de confluência nas diferentes propostas teórico-metodológicas que conhecemos coincidem em considerar a sistematização de experiências como um processo: a) de reflexão individual e coletiva; b) em torno de uma prática realizada ou vivida; c) que realiza uma reconstrução organizada do ocorrido nela; d) que provoca um olhar crítico sobre a experiência; e) que produz novos conhecimentos (JARA, 2006, p. 78).

O eixo central do processo de sistematização pode ser compreendido como um "fio condutor que atravessa a experiência e se refere aos aspectos centrais dessa(s) experiência(s) que interessa sistematizar" (JARA, 2006, p. 82).

Um recurso metodológico que pode guiar o processo de investigação da prática no contexto da formação de professores é o DF, cuja utilização permite que o professor reflita sobre o seu ponto de vista com relação à dinâmica metodológica envolvida. O DF é um instrumento que pode servir de guia para a reflexão e pesquisa da prática, pois possibilita a SE (PORLÁN; MARTÍN, 2001), o que também é defendido por Zabalza (2004).

Zeichner (2008) defende a elaboração de narrativas como metodologia de investigação da prática docente, favorecendo a autonomia docente por meio do desenvolvimento de profissionais pesquisadores reflexivos. No entanto, para que a IFA seja melhor demarcada ao professor que escreve, além da reflexão individual, possibilitada pela escrita narrativa no DF, é preciso um processo de reflexão coletiva desencadeado pela $\mathrm{SE}$ em grupos de formação (BREMM, 2019). Podemos depreender que uma mesma experiência pode ser sistematizada sob diferentes enfoques; em razão disso, ao se iniciar um processo de sistematização é necessário definir previamente o eixo que será privilegiado, delimitando problemas práticos e realinhandoos a uma espiral autorreflexiva (ALARCÃO, 2010).

Olhando por meio de uma perspectiva metodológica, segundo Santos e Castro (2014), a sistematização contribui com os processos desenvolvidos por educadores, pois está centrada na possibilidade de visualização de seu processo como constituição de identidade profissional docente e como possibilidade de sistematização do conhecimento. Isso ocorre a partir do processo de reflexão-ação-reflexão, proporcionado pela metodologia de sistematização, tanto em ações desenvolvidas no âmbito de seu campo de atuação como nos processos de formação continuada (ALARCÃO, 2010; SANTOS; CASTRO, 2014).

No Brasil, "existem poucas reflexões sistematizadas sobre o tema, embora trabalhos nesse sentido existam desde a década de 60, especialmente ligados a atividades de educação de adultos e práticas de formação de pequenos agricultores” (MEIRELLES, 2007, p. 48). A conjuntura política brasileira da época foi responsável por impedir a continuidade de várias dessas atividades, por meio da repressão a atividades de caráter crítico imposta pela ditadura 
militar; no entanto, recentemente observamos novamente uma disseminação da prática da SE no Brasil (MEIRELLES, 2007).

Compreendemos, portanto, que a SE e a IFA estão amalgamadas pelos seus princípios, a saber: analisar criticamente as práticas visando à transformação das mesmas e à melhoria dos contextos; compartilhar saberes e aprendizagens no/do/para o coletivo. Defendemos, com base nas referências já mencionadas nesta seção do artigo, a importância dos seguintes elementos no processo de SE: a reflexão crítica; a geração de saberes/conhecimentos; a reconstrução/transformação da prática; a interpretação e análise dos cenários e contextos; e o diálogo. Ressaltamos, no entanto, que o conceito de SE, neste ponto de nossa defesa, ainda se encontra em expansão, pois, para além das construções teóricas da literatura da área, as pesquisas brasileiras sobre formação de professores são indispensáveis à ampliação e aprofundamento deste conceito.

Para tanto, na sequência, destacamos discussões com base nos conceitos de SE utilizados pelos autores de dissertações e teses brasileiras, a fim de compreender os conceitos que movimentam esse processo investigativo/formativo, na busca de formular um conceito possível para as necessidades da formação de professores de Ciências, enfoque que temos investigado.

\section{DAS PESQUISAS AOS CONCEITOS E ENFOQUES/ELEMENTOS NECESSÁRIOS}

Nossas intenções de pesquisa acerca de compreender melhor o cenário brasileiro, no que diz respeito à $\mathrm{SE}$, nos levaram a compreender os principais conceitos e referenciais que movimentam esse processo de investigação, formação e aprendizagem. Tal inquietude nos desafiou em direção do aprofundamento do conceito de SE, verificando como cada conceito pode contribuir para a generalização do conceito que buscamos e estamos a formular para defender como proposição possível aos processos de formação de professores.

Olhando para o contexto brasileiro, as pesquisas analisadas demonstram que os estudos empreendidos acerca da SE e que estão voltados para a formação de professores, têm sido mais desenvolvidas na região Sudeste (10:14), Sul (2:14), Norte e Nordeste (1:14). Na região Sudeste, cinco trabalhos são pertencentes ao estado de São Paulo, três são do estado de Espírito Santo e dois são de Minas Gerais. Os trabalhos da região Sul são todos pertencentes ao estado do Rio Grande do Sul. O trabalho da região Norte é do estado do Amazonas e o trabalho da região Nordeste é originado do estado de Pernambuco. 
Podemos destacar que a temática da SE, no que diz respeito à formação de professores, ainda vem sendo pouco discutida. A preocupação com o tema fica mais restrita às regiões Sudeste e Sul, que compreendem praticamente todos os trabalhos encontrados em nossa busca. Acreditamos que este resultado tenha ligação com o fato de estas serem as regiões onde os programas de Pós-Graduação são mais numerosos, uma vez que podemos encontrar junto à Plataforma Sucupira ${ }^{6}$ a oferta destes programas nas áreas de Educação e Ensino com maior ocorrência justamente nas regiões Sudeste (1999), Sul (984) e Nordeste (946), sendo que apenas 384 estão localizados na região Centro-Oeste e 273 na região Norte (dados de 2018).

Podemos perceber, assim, como as pesquisas brasileiras com o viés da SE ainda são incipientes, principalmente no contexto da formação de professores ao qual nos dedicamos, o que também justifica o recorte para esta temática e não especificarmos formação de professores de Ciências, enfoque principal de nossas investigações e que demonstra a necessidade de maiores esforços de investigação com relação a esta temática. Diante disto, percebemos a importância de observarmos os conceitos que orientam as discussões presentes nos trabalhos acima apresentados.

Assim, com vistas a ampliar a compreensão do conceito de SE de forma que ele melhor atenda e qualifique processos de formação de professores, apresentamos a discussão analisando os conceitos que os trabalhos apresentam sobre a SE, presentes no Quadro 2.

\begin{tabular}{|c|c|c|c|}
\hline $\begin{array}{l}\text { Identificação do } \\
\text { Trabalho }\end{array}$ & $\begin{array}{l}\text { Unidades de significado } \\
\text { Exemplos }\end{array}$ & Categorias Iniciais & $\begin{array}{c}\text { Categorias } \\
\text { Intermediárias }\end{array}$ \\
\hline $\begin{array}{l}\text { T5, 2011; T6, 2016; } \\
\text { D5, 2013; D1, 2008; } \\
\text { D2, 2008; T4, 2009; } \\
\text { D7, 2016; T7, } 2017\end{array}$ & $\begin{array}{l}\text { "Sistematização como atividade reflexiva } \\
\text { de suas práticas" (T 5, 2011, p. 295) }\end{array}$ & $\begin{array}{l}\text { Sistematização como } \\
\text { reflexão da prática }\end{array}$ & \multirow[t]{4}{*}{$\frac{\text { Sistematização }}{\underline{\text { de Práticas }}}$} \\
\hline D4, 2012; D7, 2016 & $\begin{array}{l}\text { É o pensar sobre a realidade vivida-sentida } \\
\text { que pode, através da problematização, } \\
\text { abrir novas possibilidades para o ato } \\
\text { criativo (D4, 2012, p. 94) }\end{array}$ & $\begin{array}{c}\text { Sistematização como } \\
\text { problematização da prática }\end{array}$ & \\
\hline T6, 2016; T1, 1995 & $\begin{array}{l}\text { ressignificar o vivido é situá-lo no campo } \\
\text { da subjetividade, um terreno sabidamente } \\
\text { avesso a padronizações (T6, 2016, p. 32) }\end{array}$ & $\begin{array}{l}\text { Sistematização como } \\
\text { transformação da prática }\end{array}$ & \\
\hline D6, 2015; T4 2009 & $\begin{array}{l}\text { Sistematização é assumida como forma de } \\
\text { revisar a prática e teorizar sobre ela (D6, } \\
\text { 2015, p.8) }\end{array}$ & $\begin{array}{l}\text { Sistematização como } \\
\text { revisão }\end{array}$ & \\
\hline
\end{tabular}

\footnotetext{
${ }^{6}$ É uma importante ferramenta para coletar informações, realizar análises e avaliações e ser a base de referência do Sistema Nacional de Pós-Graduação (SNPG). Link de acesso: https://sucupira.capes.gov.br/sucupira/. Dados obtidos em 23 de Maio de 2020.
} 


\begin{tabular}{|c|c|c|c|}
\hline $\begin{array}{l}\text { D6, 2015; T5, 2011; } \\
\text { D5, 2013; D3, 2009; } \\
\text { T3, 2007; T1, 1995; T2, } \\
\text { 2005; D2, 2008; T7, } \\
2017\end{array}$ & $\begin{array}{l}\text { Sistematização de suas experiências por } \\
\text { meio do desenvolvimento da pesquisa (D5, } \\
\text { 2013, p. 96) } \\
\text { Sistematização de experiências como } \\
\text { pesquisa participativa entre professores } \\
\text { (T1,1995 p.8) }\end{array}$ & $\begin{array}{c}\text { Sistematização como } \\
\text { investigação participativa } \\
\text { ou investigação dialógica }\end{array}$ & $\begin{array}{l}\frac{\text { Sistematização }}{\underline{\text { como }}} \\
\underline{\text { investigação }}\end{array}$ \\
\hline T4, 2009; T7, 2017 & $\begin{array}{l}\text { A sistematização nesta pesquisa foi } \\
\text { concebida como instrumento teórico- } \\
\text { metodológico }(T 4,2009, p .8)\end{array}$ & $\begin{array}{c}\text { Sistematização como } \\
\text { instrumento/estratégia } \\
\text { metodológica de trabalho }\end{array}$ & \\
\hline $\begin{array}{l}\text { T5, 2011; D5, 2013; } \\
\text { T2, 2005; T4, 2009; } \\
\text { T7, } 2017\end{array}$ & $\begin{array}{l}\text { Sistematização como elemento formativo } \\
\text { para o professor (T5, 2011, p. 276) } \\
\text { Sistematização de práticas é o primeiro } \\
\text { movimento de auto formação dos } \\
\text { professores (D5, 2013, p. 43) }\end{array}$ & $\begin{array}{c}\text { Sistematização como } \\
\text { processo/elemento } \\
\text { formativo/educativo }\end{array}$ & $\frac{\frac{\text { Sistematização }}{\text { como formação }}}{\underline{\underline{\text { coletiva })}}}$ \\
\hline $\begin{array}{l}\text { D5, 2013; T4, 2009; } \\
\text { D7, } 2016\end{array}$ & $\begin{array}{l}{[\ldots] \text { sistematização, neste trabalho, foi }} \\
\text { tomada como instrumento de construção } \\
\text { da memória }(T 4,2009 \text {, p. } 20)\end{array}$ & $\begin{array}{l}\text { Sistematização como } \\
\text { construção da } \\
\text { memória/identidade } \\
\text { através de narrativas }\end{array}$ & \\
\hline T7, 2017 & $\begin{array}{l}\text { [...] a sistematização é um processo em } \\
\text { espiral, no qual vão ocorrendo de maneira } \\
\text { simultânea, mas com ênfases diferentes: a } \\
\text { construção do objeto, a reconstrução } \\
\text { histórica, a análise e interpretação, a } \\
\text { formação, a participação e a socialização } \\
\text { dos resultados, de modo a observar a } \\
\text { tomada de decisões e demarcação de } \\
\text { ênfases a cada momento do processo (T7, } \\
\text { 2017, p. 71) }\end{array}$ & $\begin{array}{c}\text { Sistematização como um } \\
\text { processo em espiral }\end{array}$ & \\
\hline $\begin{array}{l}\text { D4, 2012; T6, 2016; } \\
\text { T2, 2005; T4, } 2009\end{array}$ & $\begin{array}{l}\text { [...] sistematização torna-se um } \\
\text { instrumento capaz de contribuir para a } \\
\text { percepção mais ampla da realidade vivida } \\
\text { e das implicações que têm as ações } \\
\text { individuais e coletivas na reprodução de } \\
\text { determinadas estruturas de poder (D4, } \\
\text { 2012, p. 93) }\end{array}$ & $\begin{array}{c}\text { Sistematização como ação } \\
\text { individual e coletiva }\end{array}$ & \\
\hline $\begin{array}{l}\text { D4, 2012; D6, 2015; } \\
\text { T1, 1995; T4, 2009; } \\
\text { D7, 2016; T7, 2017 }\end{array}$ & $\begin{array}{l}\text { É um processo de produção do } \\
\text { conhecimento. (D4, 2012, p.94) } \\
\text { "[...] saberes experienciais capazes de } \\
\text { propor reflexões das ações que ocorrem no } \\
\text { local de trabalho" (D7, 2016, p.50) }\end{array}$ & $\begin{array}{l}\text { Sistematização como } \\
\text { Fonte/Produção/ } \\
\text { Construção de } \\
\text { conhecimento/saberes }\end{array}$ & $\begin{array}{l}\frac{\text { Sistematização }}{\underline{\text { de }}} \\
\frac{\text { conhecimentos/ }}{\underline{\text { Saberes }}} \\
\underline{\text { Docentes }}\end{array}$ \\
\hline
\end{tabular}

Quadro 2 - Conceitos de Sistematização encontrados nos trabalhos Fonte: Produção do autor (2020)

A análise dos dados seguindo os princípios da ATD foi iniciada pela fragmentação/desconstrução do corpus de pesquisa. Assim, originaram-se 66 Unidades de Significado (US), que foram selecionadas com foco no conceito de SE dos autores das pesquisas. Consideramos os termos mais recorrentes nestas US para a realização da categorização, ressaltando que as categorias são "opções e construções do pesquisador, valorizando determinados aspectos em detrimento de outros" (MORAES; GALIAZZI, 2011, p. 139), destas US emergiram 11 categorias iniciais e quatro categorias intermediárias apresentadas no Quadro 2 e que serão discutidas a seguir. 
A categoria intermediária, denominada de Sistematização de Práticas, engloba quatro categorias iniciais que, juntas, contêm 18 US. Nas teses e dissertações analisadas nesta categoria (10), os autores conceituam “[...] a sistematização de experiência como proposta reflexiva sobre as práticas, permite que os seus sujeitos compreendam seu fazer"7 (T7, 2017 p.72). A SE também é assumida “como forma de revisar a prática e teorizar sobre ela” (D6, 2015, p.8), em que os participantes do processo de SE se "voltam a ele para testar, produzir novas relações e, significados e desta forma, gerar transformações” (T1, 1995, p. 105).

Portanto, a categoria de Sistematização de Práticas abarca trabalhos que conceituam o processo de SE como momentos de reflexão sobre a prática da sala de aula. Esses momentos normalmente estão associados e têm início com a rememoração/revisão das suas atividades docentes, momento em que o professor passa a questionar a sua prática em busca de transformar e melhorá-la, pois "pensar sobre a realidade vivida-sentida pode, através da problematização, abrir novas possibilidades para o ato criativo" (D4, 2012, p.94). Percebemos, ao longo da análise destas teses e dissertações, que o conceito de SE está centrado na prática do professor e na sua reflexão sobre ela, sendo esta, portanto, uma reflexão individual como coadunado por Gauthier et al. (2006), porém foi possível notar também referência ao pensamento de Carr e Kemmis (1998). Analisando as US, fica claro que, na concepção destes autores, "a sistematização realimenta a prática" (FALKEMBACH, 1991, p. 13), visto que as nossas experiências são passíveis de transformações e melhorias no processo de SE, por meio deste processo as experiências se convertem em importante forma de aprendizagem teórico-prática, inclusive "para contribuir com a construção de uma teoria que responda à realidade" e "permita orientar nossa prática à sua transformação" (JARA, 2006, p. 37). A SE instiga momentos de reflexão docente, o que torna possível "formar professores que venham a refletir sobre a sua prática, na expectativa de que a reflexão será um instrumento de desenvolvimento do pensamento e da ação" (GARCIA, 1992, p. 60).

Outra categoria intermediária que surgiu da análise está voltada para os trabalhos (10) que concebem a Sistematização como investigação. Esta categoria é composta por 15 US, que estão distribuídas em duas categorias iniciais. Estes trabalhos pontuam a SE como metodologia ou instrumento de pesquisa, salientando ainda que "a sistematização precisa ser assimilada pela equipe de educadores como uma ferramenta de trabalho" (T4, 2009, p. 37).

Nestes trabalhos, a Sistematização além de ser concebida como processo de pesquisa sobre a prática, também leva em conta a importância da reflexão no coletivo que não foi

\footnotetext{
${ }^{7}$ Optamos por utilizar o recurso tipográfico itálico nas citações advindas das teses e dissertações analisadas, como forma de dar destaque aos dados da coleta ao longo do texto.
} 
apontada na categoria anterior, apresentando ligação com as defesas de Zeichner (2008). Como podemos observar em T1 (1995, p. 8), que aponta para a SE “como pesquisa participativa entre professores”, que se caracteriza “como um processo que permite além da organização e análise dos resultados a reflexão crítica e coletiva de todo o processo onde a participação dos sujeitos envolvidos busca proporcionar ensinamentos aprendizagens e trocas de experiências" (D2, 2008, p. 9). Segundo Alarcão (2010), a reflexão deve ser compreendida como processo de reflexão para a ação, que ocorre por meio de processos de observação e reflexão, permitindo que a experiência seja analisada e conceitualizada, em que compreensões e conceitos oriundos da transformação são guias para as novas experiências. Esta pesquisa sobre a prática é um momento de "intervenção que nasce e serve para própria prática do professor envolvido na IFA" (GÜLLICH, 2013, p. 223).

A terceira categoria intermediária engloba os trabalhos (8) que compreendem a Sistematização como formação coletiva. Esta categoria é resultante do agrupamento de quatro categorias iniciais, formadas por 18 US. Diferentemente das categorias intermediárias anteriores, nesta categoria a SE é concebida como processo de formação para os professores, tratando-se “do processo formativo inicial e, também continuado” (T5, 2011, p. 277). A SE é “o primeiro movimento de autoformarão dos professores” (D5, 2013, p. 43) é também “[...] um processo tecido a muitas mãos" (T6, 2016, p.32). Na percepção e experiência de pesquisa destes autores, a SE pode ser compreendida como processo de formação, pois a reflexão sobre as práticas que ocorrem no coletivo atua durante a SE como momento de construção "de sua identidade” (D5, 2013, p. 96) docente. A SE torna-se estratégia de formação à medida que favorece o processo de reflexão crítica entre os professores por meio de elementos como a escrita, o espelhamento de práticas e o diálogo formativo, elementos constitutivos da formação em Ciências (BREMM, 2019), no que o desenvolvimento de uma IFA crítica exige o diálogo coletivo sobre as experiências (CARR; KEMMIS, 1988).

Esta concepção de SE dá ênfase ao processo de construção de narrativas tanto de forma verbal como escrita, como percebemos em T4 (2009, p. 20) que: “[...] a partir das várias narrativas se pode construir essa memória e o texto que a expressa". Com o passar do tempo, o processo de construção de narrativas "tende a fazer com que a escrita se torne parte de sua formação/constituição, assumindo a forma desejada: a pesquisa na ação docente" (GÜLLICH, 2013, p. 230). Por fim, os trabalhos que conceituavam a SE como formações coletivas denotam que este processo ocorria em espiral; portanto, a reflexão sobre a prática se dá de forma cíclica, contínua e desenvolvimentista (ALARCÃO, 2010, p. 53). 
A última categoria intermediária a surgir foi a de Sistematização de conhecimentos/ Saberes Docentes e partiu de (seis) trabalhos. Esta categoria é composta por um total de 15 US e engloba uma categoria inicial. As categorias intermediárias anteriores estavam voltadas para o processo de reflexão da prática, ou pesquisa sobre a prática, sempre visando à melhoria ou transformação da mesma, ou ainda sendo este um momento de autoformação para o professor. Nenhuma delas, no entanto, denota o processo de SE como momento de construção de conhecimentos/saberes sobre a profissão docente, características que emergem nesta concepção, como verificamos em "a sistematização da experiência permite uma forma diferenciada de construção do conhecimento através de um olhar crítico dos próprios envolvidos na prática social" (D4, 2012, p. 92). Nestes trabalhos, podemos verificar a concepção de que a construção do conhecimento/saber experiencial culmina na transformação da prática docente, percepção que recobra as defesas de Tardif (2002) e Guathier (2006). Portanto, a aprendizagem desencadeada pela SE se constitui em "um processo coletivo de produção de conhecimento que acontece a partir de práticas sociais concretas" (FALKEMBACH, 1991, p.11).

$\mathrm{Na}$ análise das teses e dissertações, buscamos destacar as diferenças conceituais apresentadas nos trabalhos sobre a SE, a fim de apresentar como cada conceito contribuiu para a generalização do conceito que buscamos aprofundar e defender um conceito de SE em perspectiva, ou seja, que esteja voltado aos processos de investigação e formação de Professores de Ciências (IFAC). Portanto, foram destacados os elementos que cada categoria inicial e intermediária trouxeram para a formulação do conceito (re)significado/categoria final que defendemos como nossa proposição, apresentado a seguir.

\section{UMA SISTEMATIZAÇÃO DE EXPERIÊNCIAS POSSÍVEL PARA FORMAR PROFESSORES (DE CIÊNCIAS): PROPOSIÇÃO}

Procedemos a esta investigação, desde as intenções até à análise, cotejando as pesquisas brasileiras sobre o tema com a literatura da área para propormos aprofundamento conceitual sobre a SE. Portanto, aqui apresentamos a categoria final, que compreende a nossa concepção sobre o processo de SE a partir dos elementos anteriormente citados/analisados. Concebemos a Sistematização de Experiências como um macroprocesso central ao desencadeamento da IFAC.

A defesa desta concepção de SE está pautada no fato de compreendermos, a partir do estudo feito, que a ação de SE é capaz de desencadear processos reflexivos, desenvolvendo a 
autonomia do professor e a sua criticidade em busca da transformação da prática docente, assim como a IFA preconiza. Durante a formação de professores, bem como a investigação sobre esta, o processo de SE permite a compreensão de nossas experiências, o que culmina na melhoria das mesmas, permite compartilhar aprendizagens em coletivo e, assim, se encontrar em experiências similares (ALARCÃO, 2010). O processo de SE contribui por meio de conhecimentos oriundos de experiências concretas para a reflexão teórica, fazendo parte desse processo as etapas de planejamento, ação, reflexão, replanejamento, nova ação e reflexão, etapas estas que constituem a espiral autorreflexiva do processo de IFAC (CARR; KEMMIS, 1988; CONTRERAS, 1994; ALARCÃO, 2010; GÜLLICH, 2013).

Concordamos com Jara (2006), que apresenta a SE como fator indispensável para a formação docente, pois, diferentemente de outros esforços reflexivos, a SE permite compreender a relação existente entre as diferentes etapas de uma atividade prática, apontando os elementos mais relevantes, os momentos significativos que marcaram a prática e que poderiam ser alteradas durante o encaminhamento da mesma em busca da melhoria da prática.

Defendemos que a SE voltada para a formação de professores ocorra por meio da escrita narrativa em DF, por ser este ser um instrumento que guia a reflexão e pesquisa da prática que permite a SE de forma escrita pelo intermédio de reflexões individuais. Estas, ao serem externalizadas pelo diálogo formativo, permitem a SE de forma coletiva, desencadeando um segundo momento de reflexão, agora mais complexo: a reflexão coletiva.

Além disso, para que a dimensão formativa da IFA atinja performance plena e resulte em aquisição de conhecimentos, faz-se importante que a IFA seja acompanhada por uma metarreflexão crítica oriunda do processo de SE ocorrido (CARR; KEMMIS, 1988; ALARCÃO, 2010). É importante que haja vigilância epistemológica de cunho teórico-prático em relação ao processo de SE; esse papel cabe aos participantes da IFA, mas sobretudo aos professores formadores (GÜLLICH, 2013), que atuarão na coordenação, planejamento e organização das atividades investigadas durante o desenvolvimento da SE. O zelo que é empreendido pelos professores formadores contribui diretamente para a efetivação da IFA.

Destacamos que o conceito de SE ainda está em desenvolvimento, encontra-se em expansão, pois estamos em movimento de constantes aprendizagens em relação ao tema, mas no que tange à formação de professores (de Ciências) tendo como base a revisão de teses e dissertações brasileiras e a revisão da literatura da área, defendemos a concepção de SE como macroprocesso central ao desencadeamento de elementos formativos da IFAC. 


\section{REFERÊNCIAS}

ALARCÃO, I. Professores reflexivos em uma escola reflexiva. 7.ed. São Paulo: Cortez, 2010.

CARO, M. C. G. Reconstrucción narrativa de la experiencia educativa "diálogos pedagógicos": Mujeres tejen memoria desde las voces de la experiência. Orientador: Andrea Ciacchi. 2019. Dissertação (Mestrado em Estudos Latino-Americanos), Universidade Federal da Integração Latino-Americana, Foz do Iguaçu, 2019.

CARR, W.; KEMMIS, S. Teoria crítica de la enseñanza: investigación-acción en la formación del profesorado. Barcelona: Martinez Roca, 1988.

BREMM, D. O papel da Sistematização da Experiência na Formação de Professores de Ciências e Biologia. Orientador: Roque Ismael da Costa Güllich. 2019. Trabalho de Conclusão de Curso (Ciências Biológicas-Licenciatura), Universidade Federal da Fronteira Sul, Cerro Largo, 2019.

FALKEMBACH, E. M. F. Sistematização. Ijuí: Editora Unijuí, 1991.

FALKEMBACH, E. M. F. Sistematização... Juntando cacos, construindo vitrais. In: FALKEMBACH, E. M. F. O que é sistematização? Uma pergunta. Diversas respostas. Cadernos da Cut, São Paulo: CUT/SNF, 2000.

FREIRE, P. Pedagogia do Oprimido. 40. ed. Rio de Janeiro, Paz e Terra, 2005.

GARCIA, C. M. A formação de professores: novas perspectivas baseadas na investigação sobre o pensamento do professor. In: NÓVOA, A. Os professores e sua formação. 2. ed. Lisboa: Instituto Inovação Educacional, 1992.

GAUTHIER, C. et al. Por uma teoria da pedagogia: pesquisas contemporâneas sobre o saber docente. 2. ed. Ijuí: Editora Unijuí, 2006.

GÜLLICH, R. I. da C. Investigação-Formação-Ação em Ciências: um caminho para reconstruir a relação entre livro didático, o professor e o ensino. Curitiba: Editora Prismas Ltda, 2013.

JARA, O, H. Para Sistematizar Experiências. 2. ed. Brasília: Ministério do Meio Ambiente, 2006.

KIEREPKA, J. S. N. GÜLLICH, R. I. da C. O desencadeamento do diálogo formativo pelo compartilhamento de narrativas em um contexto colaborativo de formação de professores de Ciências e Biologia. REIEC, Buenos Aires, v. 12, n. 1, p. 55-67, 2016. Disponível em: https://doi.org/10.24317/2358-0399.2019v10i3.10840. Acesso em: 03 jun. 2020.

LARROSA, J. B. Notas sobre a experiência e o saber de experiência. Trad. João Wanderley Geraldi. Revista Brasileira de Educação, n. 19, 2002. Disponível em:

https://www.scielo.br/pdf/rbedu/n19/n19a02.pdf. Acesso em: 03 jun. 2020. 
MARTINIC, S. El objeto de la sistematización y sus relaciones com a evaluation y la investigación. Santiago do Chile: Fundación Universitaria Luis Amigó- CEAAL, 1998.

MEIRELLES, M. C. Conhecimento e prática social: a contribuição da sistematização de experiências. Orientadora: Ana Maria Saul. 2007. Dissertação (Mestrado em Educação) Pontifícia Universidade Católica de São Paulo: São Paulo, 2007.

MORAES, R.; GALIAZZI, M. C.. Análise Textual Discursiva. 2. ed. Ijuí- Ed. Unijuí, 2011, $224 \mathrm{p}$.

MORGAN, M. L. La sistematización: apuesta por la generación de conocimientos a partir de las experiências de promoción. In: Escuela para el Desarrollo . Materias Didácticos, n. 1, Lima, 1995.

NÓVOA, A. Formação de professores e profissão docente. In: NÓVOA, António. (Org.). Os professores e a sua formação. Lisboa: Dom Quixote, 1995.

PERSON, V.; BREMM, D.; GÜLLICH, R. A formação continuada de professores de ciências: elementos constitutivos do processo. Revista Brasileira de Extensão

Universitária, v. 10, n. 3, p. 141-147, 2019. Disponível em: https://doi.org/10.24317/23580399.2019v10i3.10840. Acesso em: 03 jun. 2020.

PORLÁN, R.; MARTÍN, J. El diario del profesor: un recurso para investigación en el aula. Sevilla, Díada, 2001.

ROMANOWSKI, J. P.; ENS, R. T. As pesquisas denominadas do tipo "estado da arte". Diálogo Educacional, Curitiba, v. 6, n. 19, p. 37-50, set. 2006. Disponível em: https://www.redalyc.org/pdf/1891/189116275004.pdf. Acesso em: 03 jun. 2020.

SANTOS, K. CASTRO, A. M. Sistematizar experiências para pensar a prática na educação social. Revista Educação Popular, v. 13, n. 2, p. 36-48. 2014. Disponível em:

http://www.seer.ufu.br/index.php/reveducpop/article/view/26221. Acesso em: 03 Jun. 2020.

SOUZA, J. F. Sistematização. In: SOUZA, J. F. O que é sistematização? Uma pergunta. Diversas respostas. Cadernos da Cut, São Paulo: CUT/SNF, 2000.

TARDIF, M. Saberes docentes e formação profissional. Petrópolis: Vozes, 2002

ZABALZA, M. A. Diários de aula: um instrumento de pesquisa e desenvolvimento profissional. Porto Alegre: Artmed, 2004.

ZANON, L. B. Interações de licenciandos, formadores e professores na elaboração conceitual de prática docente: módulos triádicos na licenciatura de Química. Orientadora: Roseli Pacheco Schnetzler. 2003. Tese (Doutorado em Educação) - Faculdade de Ciências Humanas, Universidade Metodista de Piracicaba, Piracicaba, 2003.

ZEICHNER, K. M. Uma análise crítica sobre a "reflexão" como conceito estruturante na formação docente. Revista Educação e Sociedade, v. 29, n.103, p. 535-554, 2008.

Disponível em: https://www.scielo.br/pdf/es/v29n103/12.pdf. Acesso em: 03 Jun. 2020. 
Submetido em: 07 de julho de 2020 . Aprovado em: 08 de setembro de 2020. 